\title{
De l'electricitat a la fusta. Espais d'aprenentatge de la Tecnologia mitjançant projectes
}

\author{
Zulema Josa (zu.josa@gmail.com) Institut Príncep de Girona (Barcelona) \\ Esther Pintó (epinto92@gmail.com) Institut Torre Vicens (Lleida) \\ Carles Serra (rserra39@xtec.cat) Institut Marta Estrada (Granollers) \\ Jaume Feliu (jfeliua@gmail.com) Institut Salas i Xandri (Sant Quirze del Vallès)
}

Les activitats de construcció i disseny permeten orientar l'ensenyament de la Tecnologia cap a espais metodològics més contextualitzats que permeten el desenvolupament d'habilitats de planificació i gestió de projectes. L'Aprenentatge Basat en Projectes proposa per a aquest tipus d'activitats un marc de gestió d'aula i avaluació útil per a l'aprenentatge. En aquest article, es presenten quatre projectes aplicats en aules de secundària en els que els alumnes planifiquen i desenvolupen diversos projectes relacionats amb diversos materials i tècniques (fusta, electrònica) i es discuteixen aspectes metodològics clau per al seu desenvolupament.

Paraules clau: Tecnologia, ABP, Disseny, Producte.

Design and construction activities allow to teach Technology in a contextualized frame and to develop skills of planning and managing projects. Project-Based Learning propose for this kind of activities a frame for assessment and classroom management. We present four projects applied in secondary schools, where students plan and develop several projects related with several materials and technics (wood, electronics) and we discuss key methodologic aspects about the development of this kind of activities.

Paraules clau: Technology, PBL, Design, Product.

\section{INTRODUCCIÓ}

L'Educació del segle XXI ha de donar resposta als nous reptes i necessitats d'una societat tecnològica constantment canviat. Per això, el treball per Projectes i concretament l'Aprenentatge Basat en Problemes o Projectes (ABP) (Aliberas, 2008) és un nou recurs metodològic que permet el treball per competències de forma transversal donant solució als reptes que la societat ens presenta.

Però, què és un $A B P$ ? És un recurs pedagògic engrescador, tant per a l'alumnat com per al professorat, que impulsa un aprenentatge basat en competències (Rossell, 2007). Aquest mètode propugna l'adquisició de coneixement plantejant problemes de la vida real (Sala, 2007, Xarxa de Com- petències Bàsiques, 2015). L'ABP implica un ensenyament pràctic que en el procés constructiu tecnològic s'orienta a l'elaboració d'un producte que tingui sentit en el món real, el que també sol provocar que hi participin, per necessitats del producte, coneixements de Ciències o Matemàtiques, el que s'ha definit com a STEM. Aquest procés pot fer-se de forma tancada i completament estructurada, com una successió de tasques, o fer que els alumnes participin en diferents graus en la planificació i presa de decisions. De fet, el Tinkering seria l'extrem més obert, ja que s'hi proposen només els materials i els participants decideixen com treballar-los i què construir. Això, que es proposa com a via cap a la creativitat, sol també provocar una menor connexió amb el món real dels productes, que poden ser prototips de projectes més estructurats 
En aquest article presentem diverses experiències que se situen en un espai intermedi, en els que existeix un producte més o menys definit, però en el que els alumnes participen creativament en diversos punts del procés.

\section{DESCRIPCIÓ D'EXPERIÈNCIES}

\section{La cursa dels cotxes elèctrics (Jau- me Feliu)}

El projecte s'ha dut a terme amb 60 alumnes de 2n d'ESO de l'Institut Salas i Xandri. A partir del currículum que marca el Decret 187/2015, el projecte pretén cobrir continguts del bloc d'electricitat (circuits elèctrics, corrent continu, motors elèctrics i simulació de circuits) i del bloc del Procés tecnològic (planificació, construcció, redacció d'informes i comunicació de projectes). Tot el projecte està descrit en un lloc web desenvolupat pel professorat (https://sites.google.com/salasixandri.cat/cursadeco txes). En aquest, els alumnes hi troben activitats que els guien en el seguiment del projecte. Algunes activitats cal fer-les de forma individual i es registren en un document individual de cada alumne (compartit amb els professors) i d'altres s'han de fer en grup i es registren en un altre document

El projecte segueix diverses fases:

1) Previsió: en aquesta fase els alumnes es familiaritzaren amb el projecte, però sense començar a desenvolupar res. Ens assegurem que els alumnes entenguin el repte que se'ls presenta, que tinguin clar quin rol ha d'exercir cada membre del grup (ells trien els càrrecs), que identifiquin quins conceptes són els que ja coneixen i quins els caldrà aprendre i que es facin preguntes que ajudin a desenvolupar el projecte.

En aquest projecte concretament, el repte que es presentava als alumnes era el següent:

«Cada grup ha de dissenyar i construir una maqueta d'un cotxe elèctric amb comandament $a$ distància (amb cable) per seguir un circuit amb obstacles en el menor temps possible. La maqueta del cotxe que cada grup ha de dissenyar ha de ser capaç d'avançar endavant i ha de poder girar cap els dos costats. El cotxe ha de poder funcionar amb plaques solars i, quan no hi hagi sol, s'han de poder connectar unes piles en el lloc de les plaques solars».

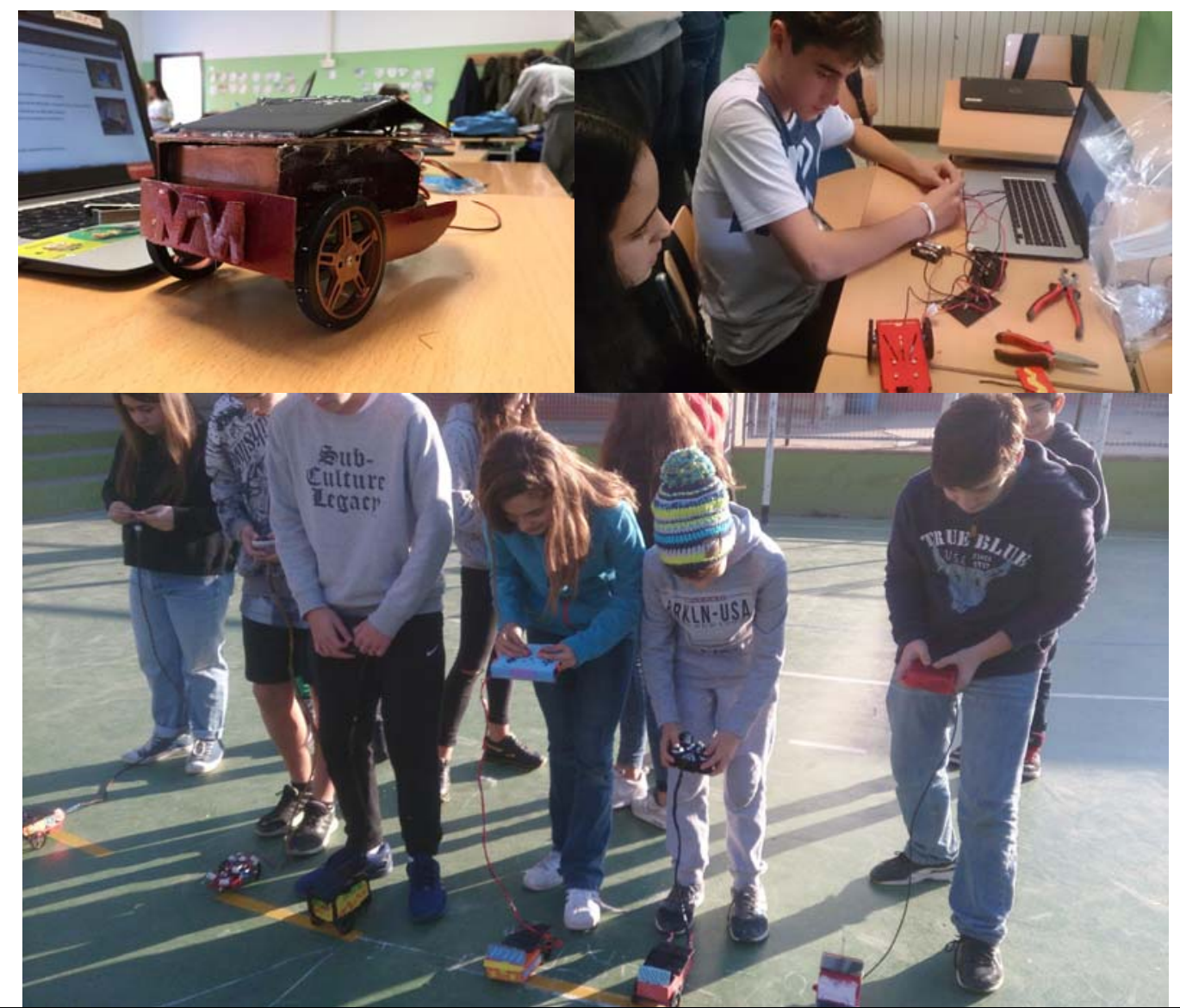

Figura 1. a) Vehicle pràcticament acabat. b) Alumnes provant circuits elèctrics. c) Tests previs a la cursa. 
2) Recerca: en aquesta part els alumnes han d'adquirir els conceptes bàsics per poder desenvolupar el projecte. No és una fase tancada, ja que un cop passin a la següent trobaran dubtes que els caldrà resoldre fent més recerca. Però les activitats guien a l'alumne en els conceptes imprescindibles per poder avançar. En aquest projecte concret, les activitats els permeten conèixer els conceptes de transformacions energètiques, de circuit elèctric i tipus de cotxes actuals.

3) Anàlisis i propostes: aquí és quan, de forma individual, fan les primeres propostes de disseny: com serà el cotxe (carrosseria) i com seria el comandament. Després, es posen en comú en grup per tal que les analitzin i triïn la solució òptima.

4) Elaboració: en aquesta fase els grups s'organitzen per construir el cotxe que han dissenyat. Cada grup és autònom per poder dividir-se tasques.

5) Avaluació: en la darrera fase els alumnes avaluen tres coses per separat. Abans de la cursa final, a través d'una rúbrica cada grup avalua el seu cotxe. Així, abans de l'avaluació del professorat, els alumnes poden fer retocs en el seu cotxe.

També avaluen als seus companys, a través d'una rúbrica disponible a la web de l'activitat.

I la darrera cosa que avaluen és el seu paper al projecte. En el document individual fan una reflexió sobre com s'han sentit, com han trebaIlat,...

Acabada la cursa i el projecte, arriba el torn de l'avaluació per part del professorat. Es revisen documents, els cotxes finals i l'actitud que han tingut els alumnes en el dia a dia del projecte. S'acaba generant un informe qualitatiu (amb els resultats de les rúbriques) i quantitatiu (amb notes de cada apartat) per tal que cada alumne entengui quins assoliments ha aconseguit i quines mancances ha tingut

\section{Dissenyem les instal-lacions d'un ha- bitatge (Esther Pintó)}

La proposta que es va plantejar va ésser " Les instal•lacions en els nostres habitatges" a l'optativa de tecnologia de 4t d'ESO de l'Institut Torre Vicens (Lleida). Aquesta es va dur a terme durant dues hores d'un trimestre amb un total de 18 alumnes organitzats en grups de tres i simulant el treball d'un gabinet tècnic.

En aquest projecte els alumnes planifiquen com han de ser les diferents instal•lacions que volem dissenyar i posteriorment implementar-les a la ma- queta de l'habitatge. Tot el projecte està realitzat amb la metodologia ABP. Els alumnes treballen per equips (Gabinets tècnics) de tres alumnes, on hi haurà un coordinador general i coordinadors de cada tasca

Després d'una presentació inicial, es planteja als alumnes estudiar, dissenyar i realitzar, la instal•lació d'algunes instal•lacions de l'habitatge. Això ho realitza cada gabinet tècnic (grup de tres alumnes) i ho duran a terme en la maqueta de l'habitatge que prèviament han dissenyat i construit.


Figura 2. a) Exemple d'un grup de treball. b) Imatge d'un plànol de la instal-lació elèctrica d'un dels grups (tasca parcial). c) Producte final del projecte. 
Els objectius de l'activitat es resumeixen en:

- Adquirir coneixements sobre les diferents instal•lacions.

- Adquirir procediments i/o habilitats en aquest àmbit. Concretament, les que fan referència a la instal•lació elèctrica.

- Ser capaç d'interpretar total la informació dels diferents plànols i diagrames de cada instal•lació.

- Adquirir les competències per realitzar el plànol, el disseny i l'aplicació de la instal•lació elèctrica.

- Crear el producte final. Implementar la instal•lació elèctrica de l'habitatge a la maqueta realitzada anteriorment

Al llarg de la seqüència, els alumnes han de donar resposta al repte i portar a terme diferents tasques: 1) Recerca de les diferents instal•lacions de l'habitatge; 2) Estudi i aplicació de cada instal•lació al nostre habitatge; 3) Disseny i realització dels plànols de les diferents instal•lacions; 4) Producte final: Implementació de la instal•lació elèctrica al nostre habitatge, memòria descriptiva i exposició. Totes i cadascuna de les diferents tasques es troben en un curs Moodle dissenyat per a dur a terme amb èxit la consecució del producte

Cal esmentar que els alumnes assoleixen els objectius d'aprenentatge al mateix temps que do- nen resposta i solució al projecte o producte plantejat. Això ho fan mitjançant un procés de recerca activa on el treball en grup de forma col-laborativa $i$ cooperativa és imprescindible. Al llarg de tot aquest procés, el professor exerceix una funció d'assessorament. En el següent enllaç trobareu tota la informació de la qual disposen els alumnes, com per exemple, les pautes, els continguts bàsics i els diferents elements facilitadors i orientadors: http://www.iestorrevicens.cat/moodle/course/view.p hp?id=521.

Per a les diferents tasques, els alumnes disposen del recolzament avaluatiu de diferents rúbriques que els permeten autoavaluar el seu procés i la qualitat dels seus productes. L'avaluació es realitza en tres moments, a l'inici, durant el procés i al final d'aquest. A l'inici, per veure si l'alumne ha entès el plantejament o la proposa a realitzar. Al llarg del procés, els alumnes disposen del recolzament avaluatiu mitjançant rúbriques que els permeten avaluar les diferents tasques parcials i la seva funció dins del grup. Al final del procés, han d'avaluar el producte realitzat, el procés en sí i els objectius assolits. Els alumnes en tot moment s'autoavaluen i avaluen als companys mitjançant rúbriques de coavaluació, com les que es mostren a la Figura 3. Totes elles estan creades i portades a terme amb l'aplicació “CoRubrics" (Feliu, 2014).

\begin{tabular}{|c|c|c|c|c|c|}
\hline (c) (1) (O) & $\frac{\text { EXCEL-LENT }}{25}$ & NOTABLE & SUFICIENT & INSUFICIENT & PES \\
\hline & 25 & 20 & 10 & 5 & \\
\hline $\begin{array}{c}\text { Puntualitar en posar-se } \\
\text { a treballea. }\end{array}$ & $\begin{array}{l}\text { Es pess a velbulari inima als } \\
\text { companys a posassh }\end{array}$ & Es posa a teballax de seguisa. & 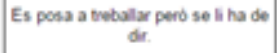 & No sti posa. & $10 \%$ \\
\hline $\begin{array}{l}\text { Organilteació de la } \\
\text { documentacio. }\end{array}$ & La guarta is cuida la presertacid. & $\begin{array}{l}\text { La guarda. la slansifica i la porta } \\
\text { sempre. }\end{array}$ & Nomulmert la guarda i la porta & $\begin{array}{l}\text { La guarda pero habitualmert no ia } \\
\text { ponta ono la troka. }\end{array}$ & $15 \%$ \\
\hline Recerca Sinformacio. & $\begin{array}{c}\text { Posa atereid es concertra i apents } \\
\text { idees. }\end{array}$ & Posa atencis i es concentra te. & Ho intenta pero is eosta & $\begin{array}{c}\text { No posa mencis, no es conceresa. } \\
\text { nho intental }\end{array}$ & 155 \\
\hline Responsabilitat & $\begin{array}{c}\text { Assumeix nesponsabilitats i in } \\
\text { dina als atres. }\end{array}$ & fa allo que se i encomara. & $\begin{array}{c}\text { Es vol ter cames de ist, no corfia } \\
\text { men els companys. }\end{array}$ & No assumeix responsabiltas. & $20 \%$ \\
\hline Presa de decisions. & $\begin{array}{c}\text { Evecha i parta do forms } \\
\text { equillorada. }\end{array}$ & 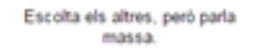 & Para peno no encola sh altres. & No parla ei escelta. & $20 \mathrm{~s}$ \\
\hline $\begin{array}{l}\text { Complimeent del pla de } \\
\text { treball. }\end{array}$ & Ho entrega bot purtualment. & $\begin{array}{c}\text { Entowega la mojonia finformaxio a } \\
\text { temps. }\end{array}$ & Entrega el que toca tard. & No entrega el que toca & $20 \%$ \\
\hline
\end{tabular}

\begin{tabular}{|c|c|c|c|c|c|}
\hline (c) (i) (-) & EXCEL-LENT & NOTABLE & SUFICIENT & INSUFICIENT & $\%$ \\
\hline Jaume Fellu (@ifellua) & 4 & 3 & 2 & 1 & \\
\hline COOPERACIO & $\begin{array}{l}\text { He participat molt activament } \\
\text { aportant idees i fent observacions } \\
\text { per aconseguir un resultat optim. }\end{array}$ & $\begin{array}{l}\text { He participat aportant idees i he fet } \\
\text { osservacions oportunes. }\end{array}$ & $\begin{array}{l}\text { He participat poc, he aportat } \\
\text { poques idees. }\end{array}$ & $\begin{array}{c}\text { No he participat ni he aportat cap } \\
\text { idea. }\end{array}$ & $30 \%$ \\
\hline $\begin{array}{l}\text { RESPONSABILITAT } \\
\text { INDIVIDUAL }\end{array}$ & $\begin{array}{l}\text { Sempre faig la feina as signada } \\
\text { sense que mho hagin de recordar. }\end{array}$ & $\begin{array}{l}\text { Nomalment faig la feina que em } \\
\text { pertoca, poques vegades mho han } \\
\text { de rec ordar. }\end{array}$ & $\begin{array}{l}\text { Se mha de recordar que he de fer } \\
\text { la feina, molt poques vegades la } \\
\text { faig de manera autónoma. }\end{array}$ & No he fet la feina. & $20 \%$ \\
\hline $\begin{array}{l}\text { DINAAMICA } \\
\text { DINTERACCIÓ }\end{array}$ & $\begin{array}{l}\text { Mhe agrupat, adaptat, he } \\
\text { acceptat... ine atavort el bon } \\
\text { ambient de treball. }\end{array}$ & $\begin{array}{l}\text { Mhe agrupat } i \text { adaptat..., i he } \\
\text { acceptat els nous companys de } \\
\text { treball. }\end{array}$ & $\begin{array}{l}\text { Mhe agrupat segons les } \\
\text { necessitats de cada moment i im'ne } \\
\text { adaptat als canvis de situacio. }\end{array}$ & $\begin{array}{c}\text { Em costa agrupar-me segons se'm } \\
\text { demana. }\end{array}$ & $20 \%$ \\
\hline PRESA DE DECISIONS & $\begin{array}{l}\text { Escolto els companys, valoro les } \\
\text { seves opinions i exposo i } \\
\text { argumento les meves. }\end{array}$ & $\begin{array}{c}\text { Escolto i accepto. I proposo } \\
\text { altematives. }\end{array}$ & $\begin{array}{c}\text { Escolto i accepto el què diuen els } \\
\text { companys. }\end{array}$ & No escolto ni pario. & $30 \%$ \\
\hline
\end{tabular}

Figura 3. Rúbriques d'avaluació i coavaluació del projecte, creades amb CoRubrics. 


\section{Disseny i fabricació digital del pro- ducte: Projecte d'un tamboret (Zule- ma Josa)}

Experiència educativa realitzada a l'Institut Príncep de Girona (Barcelona) durant el 1r trimestre del curs 2014-15 amb els alumnes de 3r d'ESO (2 grups de 15 alumnes), en col•laboració amb l'Ateneu de Fabricació Digital de Ciutat Meridiana: https://www.youtube.com/watch?v=lo61P0YWJPs.

El projecte gira al voltant de les Unitats Didàctiques de Forces i Estructures de l'àrea de Tecnologia i el Sistema Dièdric de Representació de l'àrea d'Educació Visual i Plàstica, tot treballant competències clau: la competència matemàtica, la competència artística i cultural, la competència de tractament de la informació, la competència digital, la competència lingüística i audiovisual i la d'autonomia i iniciativa personal

El projecte segueix diverses fases:

- Anàlisi: En aquesta fase s'analitzen les forces que actuen sobre els tamborets del taller de Tecnologia quan seiem en ells. A continuació, s'observa el binomi força-esforç en el disseny de cada peça, La idea a la qual s'ha d'arribar és que el disseny ha de respondre a un esforç que ha de suportar segons l'ús.

- Disseny-Idea: La pràctica consisteix en dissenyar un tamboret de fusta contraxapada. Els alumnes experimenten sense gaires inputs. En aquesta fase es fa que els alumnes utilitzin les seves mans per explicar les idees.

- Disseny-Croquis: En aquesta fase s'ha de plasmar a través d'un croquis o petites maquetes de cartró allò que en la fase anterior han explicat gestualment. En general, el primer dibuix sol comunicar molt menys que l'explicació gestual. La premissa, però, és que no se'ls digui ni si està bé o no, sinó animar-los a comprovar-ho ells mateixos.

- Disseny-Model I-II-III: En aquesta fase els alumnes comencen a afrontar el problema del disseny i el tema de Forces i Estructures. Durant el procés, el professor realitza proves destructives del models de cartró per analitzar perquè han fallat en cada cas.

- Disseny-Dibuix a escala: Una vegada s'ha arribat al disseny òptim i s'ha previst les peces necessàries, es passa la rúbrica d'autoavaluació sense puntuació del procés per obtenir el primer feedback i poder millorar o corregir l'exercici. Ara ja es pot realitzar el dibuix a escala ben acotat i que els servirà de referència per realitzar el dibuix en $C A D$ amb els programes lliures de dibuix vectorial QCAD o LibreCAD (http://librecad.org/cms/home.html).
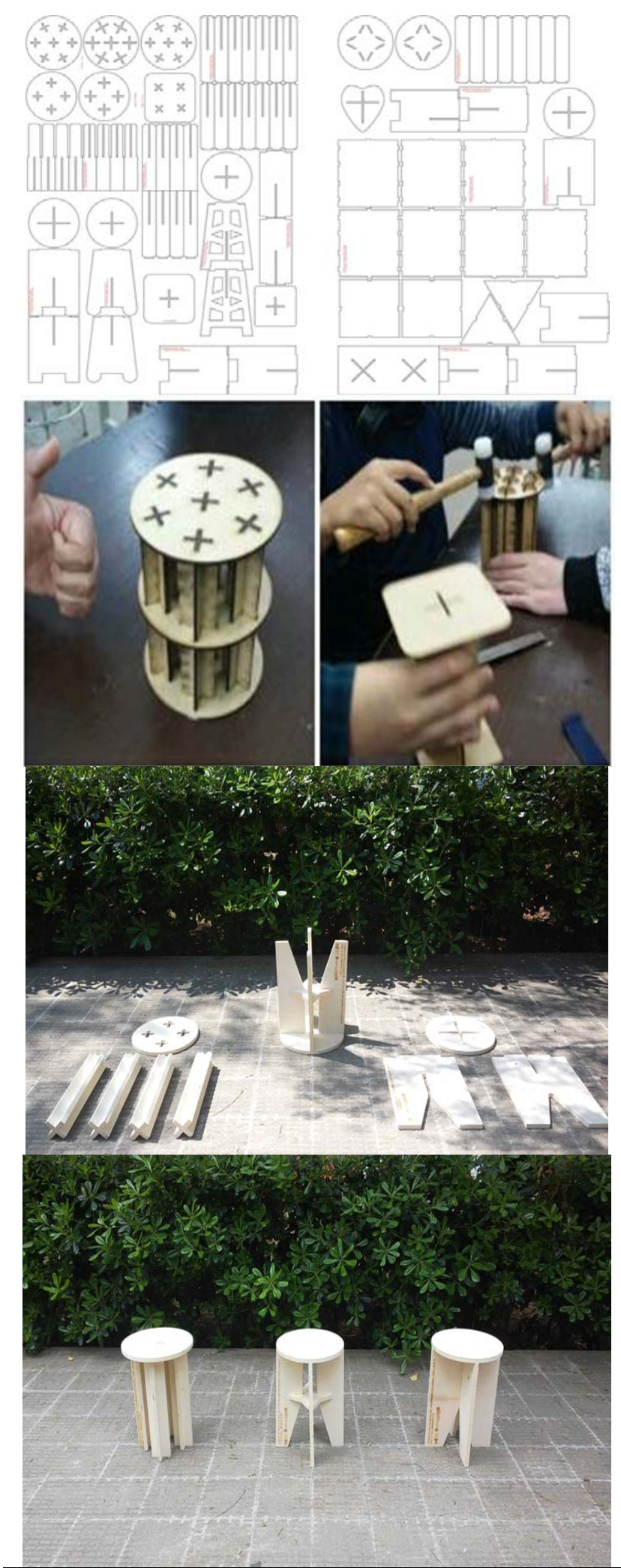

Figura 3. Imatges del procés de disseny i construcció dels tamborets. 
- Fabricació Digital a l'Ateneu de Fabricació: Amb els dissenys digitalitzats dels alumnes es rep una sessió introductòria sobre la Fabricació Digital i es comprova com l'arxiu CAD lliurat és llegit per la talladora làser al mil•límetre

- Muntatge: Es torna al taller de Tecnologia de l'Institut amb les peces de DM tallades al mil-límetre i comproven si encaixen. La majoria dels models a escala 1:3 es poden muntar amb èxit.

- Anàlisi de l'eficiència del disseny: Mitjançant la fitxa de càlcul del cost del producte final que facilita l'Ateneu, s'analitza quin és el disseny més eficient en relació resistència-cost. A partir d'aquí es dissenyen tres tamborets que resumeixen els aprenentatges adquirits. Aquests els podrem fabricar a escala real per a l'Institut.

- Fresadora de control numèric de l'Ateneu de Fabricació: Per adaptar el disseny a la fresadora de control numèric $\mathrm{i}$ al material amb què fabriquem els tamborets s'han hagut de modificar els gruixos i els encaixos del dibuix.

- Tamborets de fusta de $18 \mathrm{~mm}$ a escala real per a I'Institut: La fresadora ha tallat les peces dels nostres tamborets amb èxit. Ja a l'Institut, es llimen les peces i ens disposem a muntar-les sense claus ni cola. Els alumnes estan satisfets

Finalment, s'han avaluat, amb l'ajuda de dues rúbriques (disponibles per a la seva consulta i descàrrega

a: https://stemabp.files.wordpress.com/2016/12/rubriq ues_tamborets.docx) dos processos diferenciats. Per un costat, el procés de disseny on hi intervenen els continguts de la Unitat Didàctica de Forces i Estructures de Tecnologia. I, per l'altre, el procés de fabricació, on hi intervenen els continguts de la Unitat Didàctica del Sistema Dièdric de Representació d’Educació Visual i Plàstica.

\section{Fem un caixó flamenc (Carles Serra)}

El curs 2015-16 a l'Institut Marta Estrada de Granollers, dins l'horari de l'assignatura pròpia de I'Institut "Disseny i programació" (quatre hores lectives setmanals, agrupades en dues sessions de dues hores en les que es cursa el currículum de les matèries de Tecnologies i Visual i plàstica), es va dur a terme la construcció d'un caixó flamenc per fer-lo servir com a instrument de percussió a les classes de música de l'institut en el marc del projecte Batukada.

La proposta de projecte treballa continguts del currículum pertanyents als blocs de "materials" i "disseny i construcció d'objectes" i respecte les competències, principalment dins la dimensió d'indagació de fenòmens naturals i de la vida quotidiana, la competència número 7 "utilitzar objectes tecnològics de la vida quotidiana".

La metodologia i estructuració de les sessions es manté al llarg de diferents projectes, de manera que és coneguda per l'alumnat. Els 60 alumnes participants realitzen dins la matèria diversos projectes (construcció d'un laberint de cartró, l'arrebossat d'una construcció feta amb bales de palla, el muntatge d'una llanterna amb una agulla d'estendre i un LED, un taller d'introducció a l'electrònica, el muntatge d'uns calaixos per a l'aula de Tecnologies, el muntatge d'unes maquetes sobre les constel-lacions, molts dibuixos en perspectiva, alguns programes amb Scratch) i en tots ells l'estructuració de les sessions és:

1) Breu explicació inicial de 10-20 minuts on es proporciona la informació bàsica necessària per fer la pràctica (incloent esquemes o fotografies del procés si es considera oportú).

2) Realització de la pràctica: a partir de les explicacions inicials l'alumne s'auto-organitza per realitzar la pràctica, rebent indicacions puntuals a demanda del alumne i/o criteri del professor (80100 minuts).

3) Endreça de la pràctica i l'espai de treball (10-20 minuts).

Es tracta d'un projecte semi-estructurat (els alumnes prenen algunes decisions) i amb un objectiu extern: l'ús dels caixons com a instrument a la matèria de música. Es poden consultar fotografies del procés constructiu en: https://goo.gl/photos/53wGq2xuLivxrEmM7. L'anàlisi de l'aplicació de la pràctica (molt valorada pels alumnes) ens ha servit per a analitzar alguns dels elements relacionats amb la preparació, gestió d'aula, avaluació i finalment èxit i valoració per part de l'alumnat d'un projecte.

Algunes claus de l'activitat són:

a) L'organització en grups de 2-3 persones.

b) El treball a partir d'un encàrrec real (del departament de Música). Els caixons acabats s'utilitzaran a les classes de música i al Projecte Batukada del mateix institut.

c) El treball amb materials tècnics i diferents eines «de veritat». Entre elles el martell, que permet donar (molts) cops a alguna cosa (puntes). 


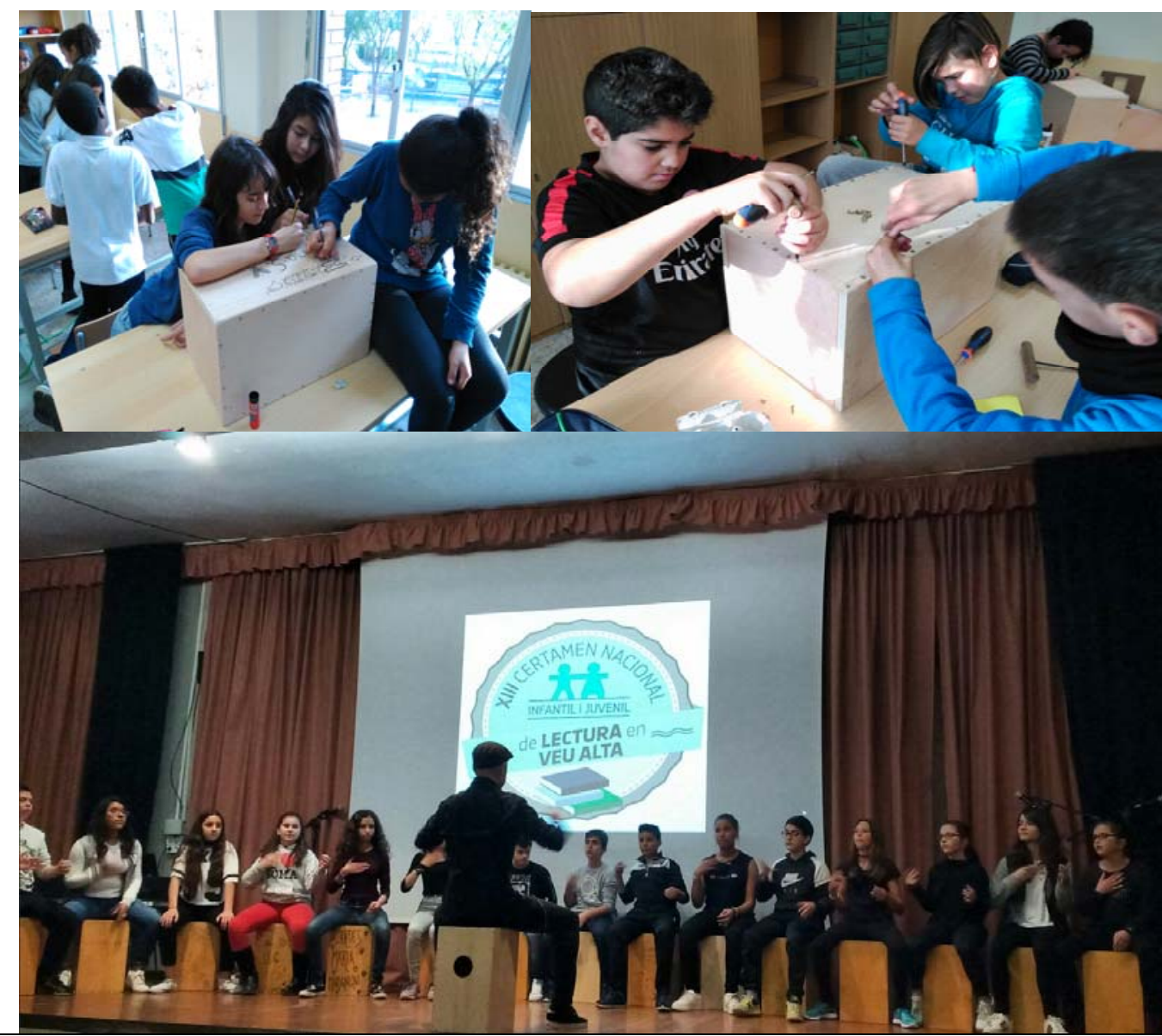

Figura 4. Alumnes treballant en equip en diverses tasques (Clavar, llimar, tallar,...) i en procés de decoració del seu caixó i utilitzant els caixons en el XIII certamen de lectura en veu alta, celebrat a Granollers el 24 de març de 2017

d) Les operacions bàsiques a realitzar són: mesurar, marcar, clavar, encolar, polir, raspar, cargolar i envernissar. Aquestes i els coneixements previs necessaris són relativament pocs i fàcils d'explicar, la qual cosa facilita la planificació i explicació de la pràctica i la realització amb èxit de la mateixa per la major part de l'alumnat.

e) Es pot decorar el producte acabat. L'alumnat pot fer la seva signatura sobre el caixó.

f) Possibilita la conversa entre companys/es i amb el professorat.

g) Afavoreix el treball cooperatiu (algunes operacions no es poden realitzar sense la col•laboració d'algun company/a).

h) Obliga a prendre petits acords (qui és el primer a fer una operació determinada, quantes puntes clava cadascú, quin tipus de decoració es farà, amb quins colors,...).

\section{CONCLUSIONS}

L'ABP fonamenta l'aprenentatge en la recerca i va més enllà d'un aprenentatge instructiu, és flexible i s'adapta a l'entorn d'aprenentatge dels nostres alumnes, promou el treball cooperatiu i l'aprenentatge entre iguals i estimula la motivació de l'alumnat al plantejar problemes reals de situacions que els hi són properes.

En l'àmbit tecnològic implica la necessitat de fer activitats pràctiques, que es poden fer seguint diferents metodologies, però que en qualsevol cas cal preparar-les amb antelació. Els projectes complexes impliquen aprenentatges parcials 0 d'operacions bàsiques que s'han de preveure en la planificació de les pràctiques. Entre altres motius per poder assegurar l'avaluació formativa durant les sessions pràctiques i l'atenció a l'alumnat amb NEE. Aquesta planificació pot ser compartida amb l'alumnat i implica també: 
- Preveure els materials i les eines que es faran servir.

- Pressupostar el material necessari i avaluar la repercussió en el pressupost anual.

- Determinar les operacions bàsiques que formen part del projecte.

- Preveure la circulació de materials, eines i persones dins de l'espai on es realitzarà la pràctica.

- Considerar els coneixements previs necessaris de l'alumnat.

- Recordar les normes i mesures de seguretat i higiene en el treball que cal respectar.

Una manera d'anticipar les dificultats és que el professorat realitzi les pràctiques amb antelació a l'activitat amb l'alumnat (independentment del seu grau de dificultat aparent), identificant punts difícils de l'activitat que no serien detectables en inici.

Aquesta planificació i organització prèvia de la feina possibilita poder realitzar l'avaluació formativa durant la realització de la pràctica (cosa desitjable, però que no sempre es compleix en les sessions pràctiques a les aules de tecnologia: a vegades l'alumnat espera l'ajut d'un professor que no arriba mai degut a diversos motius relacionats amb l'organització de l'aula, els coneixements previs necessaris, la falta de suport visual,...).

El fet de poder anar acompanyant l'alumnat en la realització de la pràctica suposa consolidar diferents aprenentatges durant la sessió (en aquest cas relacionats amb les operacions bàsiques del treball amb fusta) que repercuteixen positivament en la qualificació del projecte evitant una eventual qualificació negativa degut a haver acumulat errors durant el procés constructiu.

Cal veure que les fases proposades en els projectes anteriors no són estrictament cronològiques. Els alumnes tenen tendència a pensar-ho i quan tenen dificultats no recerquen informació per resoldre'ls. Acostumen a esperar que els professors els ho resolgui.

També cal estar atent a les preguntes que es fan en les fases inicials, ja que n'hi ha de molt bo- nes i que són molt aplicables al disseny del producte però les obliden i no les tenen en compte en la construcció.

Els projectes han introduït els alumnes en el procés creatiu del disseny i fabricació d'un producte a través de la tecnologia, el dibuix i les matemàtiques, fomentant la reflexió sobre la raó de ser de la forma i el material de cada un dels objectes quotidians. Pensem que aquest tipus d'experiències són molt positives, perquè amb el pretext d'un encàrrec, un concurs,... poden oferir un context que contribueixi a incrementar de forma positiva la rellevància que atorga l'alumnat a la matèria.

\section{AGRAIMENTS}

Aquest article recull el contingut de les ponències de les Jornades sobre Aprenentatge Basat en Projectes \#STEMABP [https://stemabp.wordpress.com/], organitzades pel CESIRE del Departament d'Ensenyament i la Fundació Catalana per la Recerca i la Innovació. Els autors agraïm al professorat i alumnat dels centres la seva participació i a Jordi Domènech la tasca d'edició de l'article.

\section{REFERÈNCIES}

ALIBERAS, J. (2008). Ensenyar Ciències a l'ESO. Revista Ciències , 9. 28-34.

FELIU, J. (2014). CoRubrics, una plantilla per avaluar amb rúbriques. Tecnocentres http://tecnocentres.org/ca/corubrics-unaplantilla-per-avaluar-amb-rubriques/

ROSELL, X. (2007). L'aprenentatge basat en problemes $i$ les seves etapes. Equip ICE-UAB, $2007 . \quad$ Barcelona. [http://www.xtec.cat/ jrosell3/metodologies/abp/]

XARXA DE COMPETÈNCIES BÀSIQUES (2015). Treball per projectes:"aprenentatge autèntic. [http://xtec.gencat.cat/web/.content/curriculum/x arxacb/documents/treball-projectesaprenentatge-autentic.pdf] 